\title{
Morphology-Variable Aggregates Prepared from Cholesterol-Containing Amphiphilic Glycopolymers: Their Protein Recognition/Adsorption and Drug Delivery Applications
}

\author{
Zhao Wang ${ }^{1,2}$, Ting Luo ${ }^{2}$, Amin Cao ${ }^{2, *}$, Jingjing Sun ${ }^{2}$, Lin Jia ${ }^{1,2, *}$ and Ruilong Sheng ${ }^{2,3, *}$ (1) \\ 1 Department of Polymer Materials, Shanghai University, 99 Shangda Road, Mailbox 152, Shanghai 200444, \\ China; wangz@sioc.ac.cn \\ 2 CAS Key Laboratory of Synthetic and Self-assembly Chemistry for Organic Functional Molecules, Shanghai \\ Institute of Organic Chemistry, Chinese Academy of Sciences, 345 Lingling Road, Shanghai 200032, China; \\ luoting@sioc.ac.cn (T.L.); jis84@pitt.edu (J.S.) \\ 3 CQM-Centro de Química da Madeira, Universidade da Madeira, Campus da Penteada, 9000-390 Funchal, \\ Portugal \\ * Correspondence: acao@mail.sioc.ac.cn (A.C.); jlsioc@shu.edu.cn (L.J.); ruilong.sheng@staff.uma.pt (R.S.); \\ Tel.: +86-21-5492-5303 (A.C. \& L.J. \& R.S.); Fax: +86-21-5492-5537 (A.C. \& L.J. \& R.S.)
}

Received: 17 January 2018; Accepted: 24 February 2018; Published: 28 February 2018

\begin{abstract}
In this study, a series of diblock glycopolymers, poly(6-O-methacryloyl-D-galactopyranose) -b-poly(6-cholesteryloxyhexyl methacrylate) (PMAgala-b-PMAChols), with cholesterol/galactose grafts were prepared through a sequential reversible addition-fragmentation chain transfer (RAFT) polymerization and deprotection process. The glycopolymers could self-assemble into aggregates with various morphologies depending on cholesterol/galactose-containing block weight ratios, as determined by transmission electronic microscopy (TEM) and dynamic laser light scattering (DLS). In addition, the lectin (Ricinus communis agglutinin II, $\mathrm{RCA}_{120}$ ) recognition and bovine serum albumin (BSA) adsorption of the PMAgala-b-PMAChol aggregates were evaluated. The SK-Hep-1 tumor cell inhibition properties of the PMAgala-b-PMAChol/doxorubicin (DOX) complex aggregates were further examined in vitro. Results indicate that the PMAgala- $b$-PMAChol aggregates with various morphologies showed different interaction/recognition features with $\mathrm{RCA}_{120}$ and BSA. Spherical aggregates $(\mathrm{d} \approx 92 \mathrm{~nm})$ possessed the highest $\mathrm{RCA}_{120}$ recognition ability and lowest BSA protein adsorption. In addition, the DOX-loaded spherical complex aggregates exhibited a better tumor cell inhibition property than those of nanofibrous complex aggregates. The morphology-variable aggregates derived from the amphiphilic glycopolymers may serve as multifunctional biomaterials with biomolecular recognition and drug delivery features.
\end{abstract}

Keywords: cholesterol; galactose; morphology; lectin recognition; DOX delivery

\section{Introduction}

Synthetic glycopolymers with saccharide grafts have attracted increasing attentions due to their interesting self-assembly behavior [1] and biological functions, which guarantee their applications as advanced biomaterials such as gene/drug carriers, immunodiagnostic reagents, and bio-targeting materials [2-4]. The saccharide-shell-bearing aggregates/assemblies with various morphologies (e.g., nanospheres, worm-like micelles, vesicles and tubules) were obtained through the nano-precipitation [5,6] or polymerization-induced self-assembly approach [7]. Meanwhile, glyco-inside nanostructures have also been reported, and their vesicle-to-micelle transition could be tuned depending on the weight ratio and protection groups of the glyco-parts [8,9]. Of particular 
interest, the Schlaad [10] and Lecommandoux [11] groups explored glycocalyx-mimicking properties of some glycopolymeric vesicles, which showed similar physico-chemical features (such as size and structure) with natural glycocalyx architectures. For the possible applications of the glyco-containing nanostructures, molecular recognition is one of the most interested areas [12]; protein crystalline frameworks [13], protein-polymer conjugates [14], complex macroscopic self-assemblies [15], and lectin-responsive hydrogels [16] have been reported. Meanwhile, it has been revealed that the availability of this multivalent recognition could be tuned via the molecular engineering of glycopolymers [17]. Chen et al. [18] found that the block and gradient structures resulted in a superior lectin binding capability than statistical sequence copolymers, and the glycopolymer nanoparticles containing branched glycol-blocks could bind more lectins than those of their linear counterparts [19]. Zhu et al. [20] disclosed that the block glycopolymers may interact with ricinus communis agglutinin II $\left(\mathrm{RCA}_{120}\right)$ to form larger clusters faster than the random copolymers. In addition, the surface density, neighboring functional groups, as well as morphologies of the glyco-nanoparticles could influence their lectin recognition. Nevertheless, the correlation between molecular recognition features and molecular architecture/assembly morphology for most of the glycopolymers are still obscure, which limits their biomedical applications.

On the other hand, molecular architecture/morphology of polymeric aggregates not only plays an essential role in their molecular recognition, but also in pharmacokinetics and drug delivery behaviors [21-23]. In particular, the aggregate morphologies (such as ellipse, cylinder, rod-like, and worm-like) have been recently disclosed to profoundly influence their endocytosis, intracellular trafficking, and tissue/organ distribution [24-27]. Mitragotri et al. [28] revealed that the particle shape instead of the size played the dominant role in phagocytosis of polystyrene particles. Likewise, poly(ethylene glycol)-block-poly(camptothecin prodrug) PEG-b-PCPTM self-assemblies with the morphologies of sphere, large compound vesicle (LCV), smooth disk, and staggered lamellae showed intriguing morphology-dependent cellular internalization, trafficking, and drug delivery [29]. It has also been revealed that the worm-like micelles (filomicelles) exhibited some advantages such as enhanced tumor accumulation and permeability and retention (EPR) effects [30,31], leading to prolonged blood circulation [32] and enhanced cellular uptake [33-35], over that of their spherical counterparts. Most recently, Gaus et al. [36] studied the cellular uptake and intracellular transport (routes) of various-shaped poly(oligoethylene glycol methacrylate)-block-poly(styrene-co-vinylbenzaldehyde) $\mathrm{P}(\mathrm{OEGMA})-b$-P(ST-co-PVBA) block copolymer nanoaggregates by pair correlation microscopy, demonstrating that rod and worm-like micelles could overcome major cellular barriers better than spherical micelles and vesicles, which resulted in more doxorubicin (DOX) release inside the nucleus.

Among the amphiphilic block copolymers (BCPs), liquid crystal BCPs (LCBCPs) could spontaneously self-assemble into a number of well-ordered micro/nano objects and showed potential applications in gene/drug delivery, electronics, advanced catalysts, nanobiotechnology, etc. [37]. In particular, cholesterol as a natural rod-like mesogenic unit has already been explored for decades [38-40]. For instance, Zhou et al. [41] synthesized triblock copolymers with polyethylene oxide (PEO) and cholesterol attached polymethacrylates, and their self-assembled hierarchical structures were disclosed to be from lamellae to cylinder, depending on the cholesterol block contents. Likewise, disk-like self-assemblies, nanospheres, and other complex nanostructures have been reported for the cholesterol-functionalized polycarbonate copolymer amphiphiles [42,43]. In our previous studies, we prepared block copolymer amphiphiles with pendant cholesterol mesogens. They could self-assemble into micro/nanoparticles with well-ordered cholesterol mesogens in the cores of cylinder micelles, solid spheres, and bowl-shaped aggregates, and in the membranes of hollow nanotubes, ellipsoidal vesicles and so forth. [44-48] Additionally, as an essential component of plasma membranes, cholesterol plays important roles in cell membrane formation, adhesion, and signal transduction, regulating lipid bilayer interaction [49] and intracellular trafficking of nanoparticles [50,51]. This brings the cholesterol-based amphiphiles new potential applications in biomedical engineering [52-54]. 
To develop glycopolymer-based aggregates with tunable morphology and to further explore the effects of molecular structure/aggregate morphology on their lectin recognition and drug delivery manners, in this work, a new series of poly(6-O-methacryloyl-D-galactopyranose)-b-poly(6-cholesteryloxyhexyl methacrylate) (PMAgala-b-PMAChol) glycopolymers with galactose and cholesterol grafts were prepared through reversible addition-fragmentation chain transfer (RAFT) polymerization and successive trifluoroacetic acid (TFA)-mediated deprotection, and their structures were characterized. Then, self-assembled PMAgala-b-PMAChol aggregates with distinct morphology features were achieved by nanoprecipitation method, and the effects of glycopolymer structure/aggregate morphology on lectin binding and bovine serum albumin (BSA) adsorption were examined in aqueous media. Furthermore, employing the PMAgala- $b$-PMAChol aggregates as potential drug carriers, the DOX loading capacity, the morphology of the PMAgala-b-PMAChol/DOX complex aggregates, and related DOX delivery properties in human hepatocarcinoma SK-Hep-1 cells were investigated and discussed.

\section{Experimental Section}

\subsection{Materials}

6-Cholesteryloxyhexyl methacrylate (MAChol), 6-O-Methacryloyl-1,2:3,4-di-O-isopropylidene-D -galactopyranose (MAIpGP), and RAFT agent of 4-cyano-4-(dodecylsulfanyl thiocarbonyl) sulfany pentanoic acid (CDP) were synthesized and purified in similar way as described in a previous work [52]. Poly(ethylene glycol) with a molecular weight of 5000 Da (PEG-5K) and branched polyethylenimine with molecular weight of 25,000 Da (PEI-25K) were purchased from Sigma-Aldrich (St. Louis, MO, USA) and Fluka (Buchs, Switzerland), respectively. $N, N^{\prime}$-azobis (isobutyronitrile) (AIBN, 98\%, Shanghai Sinopharm Chemical Reagent Co. Ltd., Shanghai, China) was recrystallized twice in methanol prior to use. Toluene solvent was refluxed over metallic sodium, and freshly distilled before use. All other solvents and chemicals purchased from commercial suppliers were used as-received. In addition, cellulose dialysis membrane (MWCO: $3500 \mathrm{Da}$ ) was bought from Shanghai Green Bird Science \& Technology Development Co. Ltd. (Shanghai, China). Doxorubicin (DOX, 98\%) was purchased from Zhejiang Hisun Pharmaceutical Co. Ltd. (Zhejiang, China). Bovine serum albumin (BSA, Cat\#0332) was supplied from Amresco (Solon, OH, USA). Thiazoyl blue tetrazolium bromide (MTT, Cat\#M5655), Concanavalin A from Canavalia ensiformis (Con A), and Ricinus communis agglutinin II $\left(\mathrm{RCA}_{120}\right)$ were all bought from Sigma-Aldrich. Human hepatocarcinoma SK-Hep-1 cells were kindly gifted by Dr. Bo Wan of the Key Laboratory of Genetic Engineering of Fudan University (Shanghai, China).

\subsection{Analytical Procedures}

${ }^{1} \mathrm{H}$ NMR spectra were recorded at ambient temperature in $\mathrm{CDCl}_{3}$ or pyridine- $d_{5}$ on a Bruker Avance-400 FT-NMR spectrometer, operated at $400.0 \mathrm{MHz}$ for the proton nuclei. FTIR spectra were measured at room temperature on a Bio-Rad FTS- 185 spectrometer with 64 scans, spanning a spectral range of $4000 \sim 500 \mathrm{~cm}^{-1}$ with a resolution of $4.0 \mathrm{~cm}^{-1}$. Samples were prepared by pressing dry potassium bromide $(\mathrm{KBr})$ and the polymer mixture before the measurements. Oxygen elemental analysis was routinely conducted on an Elementar vario EL III system (German) in quadruplicate. Molecular weights $\left(M_{n}, M_{\mathrm{W}}\right)$ and polydispersity $\left(M_{\mathrm{w}} / M_{\mathrm{n}}\right)$ of the synthesized polymer samples were measured at $35{ }^{\circ} \mathrm{C}$ on a PerkinElmer 200 Gel permeation chromatography (GPC) equipped with refractive index detector (RI). Tetrahydrofuran (THF) was utilized as the eluent at a flow rate of $1.0 \mathrm{~mL} / \mathrm{min}$, and a series of commercial polystyrene standards (Polymer laboratories, Stockport, UK) were employed to calibrate the GPC elution traces. Particle sizes and distribution of the prepared amphiphile self-assemblies in dilute aqueous solution were analyzed at $25^{\circ} \mathrm{C}$ on a Malvern Zetasizer Nano ZS90 dynamic light scattering (DLS) instrument with incident beam at $\lambda=633 \mathrm{~nm}$ and a fixed scattering angle of $90^{\circ}$ (Worcestershire, UK). Morphologies of the synthesized amphiphile aggregates 
were visualized on a transmission electronic microscope (TEM, JEOL-1230, Tokyo, Japan) under an acceleration voltage of $80 \mathrm{kV}$. In brief, the PMAgala- $b$-PMAChol aggregate aqueous solution $(1.0 \mathrm{mg} / \mathrm{mL})$ was gradually dropped onto a 300-mesh carbon-coated copper grid, and excess fluid was removed with filter paper and further air-dried under room temperature. In this study, all TEM samples were directly observed and imaged without any further staining.

\subsection{Synthesis of Diblock PMAgala-b-PMAChol Amphiphiles}

Diblock copolymer poly(6-O-methacryloyl-D-galactopyranose)-b-poly(6-cholesteryloxyhexyl methacrylate) (PMAgala-b-PMAChol) amphiphiles were synthesized by sequential RAFT polymerization and successive TFA-mediated deprotection. Typically, MAIpGP (1.312 g, $4.0 \mathrm{mmol}$ ), CDP $(80.8 \mathrm{mg}, 0.2 \mathrm{mmol})$, and AIBN $(6.6 \mathrm{mg}, 0.04 \mathrm{mmol})$ were dissolved in freshly distilled toluene $(8.7 \mathrm{~mL})$ and placed into a Schlenk tube equipped with a magnetic stirrer. The mixture was deoxygenated with a freeze-pump-thawing cycle a minimum of three times and then immersed into an oil bath thermostated at $80^{\circ} \mathrm{C}$ for $8 \mathrm{~h}$. The reaction was stopped by cooling in ice-bath, and the reaction mixture was precipitated in cold dry hexane. After filtration, the collected precipitates were dried under vacuum to finally give poly(6-O-Methacryloyl-1,2:3,4-di-O-isopropylidene-D-galactopyranose) (PMAIpGP) powders. Furthermore, the achieved PMAIpGP was employed as the macro-RAFT agent, and predetermined amounts of PMAIpGP, AIBN, and MAChol dissolved in freshly distilled toluene were in turn placed into a Schlenk tube with a magnetic stirrer. After three cycles of freeze-pump-thawing, the Schlenk tube was immersed in an oil bath preheated at $80{ }^{\circ} \mathrm{C}$, and the reaction continued for $16 \mathrm{~h}$. Then, the reaction stopped, and final products were obtained with three precipitations in anhydrous methanol and dehydration under vacuum for $12 \mathrm{~h}$. Thereafter, the as-prepared PMAIpGP and PMAIpGP- $b$-PMAChols were deprotected at room temperature in mixed trifluoroacetic acid (TFA) and dichloromethane (DCM) $(1 / 2, v / v)$ for $32 \mathrm{~h}$, and water-soluble PMAgala and PMAgala-b-PMAChol block copolymer amphiphiles were achieved with good yields through repeated precipitation in anhydrous cold methanol and drying under vacuum.

PMAIPGP:

${ }^{1} \mathrm{H}$ NMR ( $\mathrm{CDCl}_{3}, \delta$ in ppm): 5.53 (d, Gal-H at 1 position), 4.62 (m, Gal-H at 3 position), $4.35-3.90$ (m, Gal-H at 2, 4, 5 and 6 position), $2.35\left(\mathrm{~s}, \mathrm{HOOCCH}_{2} \mathrm{R}\right)$.

FTIR (in $\mathrm{cm}^{-1}$ ): 2988, 2932, 1732, 1382, 1256, 1212, 1166, 1115, 1070, 1004, 892.

PMAIpGP-b-PMAChol:

${ }^{1} \mathrm{H}$ NMR ( $\mathrm{CDCl}_{3}, \delta$ in ppm): 5.53 (Gal-H at 1 position), 5.34 (=CHR of cholesterol), 4.65 (Gal-H at 3 position), 4.35-3.75 (Gal-H at 2, 4, 5, 6 position and $\left.\mathrm{CH}_{2} \mathrm{COOR}\right), 3.45\left(\mathrm{CH}_{2} \mathrm{OR}\right.$ of cholesterol), 3.12 (OCHR of cholesterol).

FTIR (in $\mathrm{cm}^{-1}$ ): 2934, 2886, 1730, 1464, 1381, 1254, 1212, 1167, 1111, 1071, 1005.

PMAgala- $b$-PMAChol amphiphile:

${ }^{1} \mathrm{H}$ NMR (Pyridine- $d_{5}, \delta$ in ppm): 6.90-6.50 (-OH), 6.02-5.68 (Gal-H at 1 position), 5.55 (=CHR of cholesterol), 5.35-4.00 (Gal-H at 2, 3, 4, 5 position and $\left.\mathrm{CH}_{2} \mathrm{COOR}\right), 3.65\left(\mathrm{CH}_{2} \mathrm{OR}\right.$ of cholesterol), 3.38 (OCHR of cholesterol).

FTIR (in cm ${ }^{-1}$ ): 3466, 2934, 2886, 1728, 1466, 1377, 1365, 1255, 1152, 1105.

\subsection{Self-Assembly of PMAgala-b-PMAChols in Solution}

First, the critical micelle concentration (CMC) of PMAgala-b-PMAChols was measured by utilizing pyrene as a fluorescence probe [52]. PMAgala- $b$-PMAChol self-assemblies were conducted through nanoprecipitation in a similar way as previously published [55]. In brief, the amphiphiles were dissolved in pyridine under an initial mass concentration of $3.0 \mathrm{mg} / \mathrm{mL}$, and deionized water was dropped slowly under gentle shaking to a water content of about $60 \mathrm{wt} \%$. During this procedure, 
real-time mixture solution transmittance $(T \%)$ was measured on a UV-vis spectrophotometer (UV-2800, Hitachi, Japan) at $\lambda=650 \mathrm{~nm}$, and the turbidities were calculated according to the equation as following:

$$
\text { Turbidity }(\%)=2.0-\log (T \%)
$$

When the nanoprecipitation procedure was accomplished, the mixed solution was dialyzed against deionized water using a pre-swollen cellulose membrane (molecular weight cut-off (MWCO): $3500 \mathrm{Da})$ for $48 \mathrm{~h}$ to remove residual organic solvent.

\subsection{Lectin Recognition Assay}

Lectin recognition of the PMAgala- $b$-PMAChol self-assemblies in aqueous solution was explored via the recording of turbidity change at $\lambda=450 \mathrm{~nm}$ vs. time at room temperature on a UV-vis spectrophotometer. Briefly, pre-determined amounts of lectin RCA 120 were separately placed into a PMAgala $_{18}$ solution $(0.1 \mathrm{mg} / \mathrm{mL})$ or a PMAgala- $b$-PMAChol aggregate solution $(0.1 \mathrm{mg} / \mathrm{mL}$ fixed for the PMAgala block) under gentle shaking to give mixture solutions with a series of RCA 120 mass concentration of $0.1,0.2,0.5$, or $0.8 \mathrm{mg} / \mathrm{mL}$, and light absorbances at $\lambda=450 \mathrm{~nm}$ were recorded per minute for 10 min with Con A and BSA as the controls.

\subsection{BSA Adsorption Assay}

Bovine serum albumin (BSA) was employed as a model to determine protein adsorption in aqueous solution for the PMAgala- $b$-PMAChol aggregates. BSA was first placed into the aggregate aqueous solution (fixed amphiphile aggregate mass concentration: $0.2 \mathrm{mg} / \mathrm{mL}$ or $0.5 \mathrm{mg} / \mathrm{mL}$ ) to achieve a final BSA mass concentration of $0.5 \mathrm{mg} / \mathrm{mL}$, and it was kept incubation at $37{ }^{\circ} \mathrm{C}$ for a predetermined period. Then, the solutions were vortexed and centrifuged at 16,000 rmp for $15 \mathrm{~min}$ to precipitate the BSA-adsorbed aggregates, and $1 \mathrm{~mL}$ supernatant of each solution was sampled. BSA mass concentration of the supernatant was evaluated at $\lambda=280 \mathrm{~nm}$ on UV-vis spectrophotometer. The amounts of BSA adsorbed on the amphiphile aggregates were thus estimated on the basis of the BSA calibration curve in a way previously reported [56]. Poly(ethylene glycol) with a molecular weight of $5000 \mathrm{Da}$ (PEG-5K) and branched polyethylenimine with a molecular weight of 25,000 Da (PEI-25K) were employed as the negative and positive controls, respectively.

\subsection{Preparation of the PMAgala-b-PMAChol/DOX Complex Aggregates}

DOX-loaded complex aggregates were prepared through nanoprecipitation in a similar way as aforementioned. In brief, $27.0 \mathrm{mg}$ of PMAgala- $b$-PMAChol amphiphiles and $3.0 \mathrm{mg}$ of DOX were first dissolved in $10 \mathrm{~mL}$ pyridine, and stirred at room temperature for $10 \mathrm{~h}$. Afterwards, $15 \mathrm{~mL}$ of deionized water was gradually dropped into the mixture under gentle agitation, and the mixture was dialyzed against deionized water for $48 \mathrm{~h}$ using a pre-swollen cellulose dialysis membrane (MWCO: $3500 \mathrm{Da}$ ) to give a DOX-loaded complex aggregate solution. DOX loading levels were further measured on a UV-vis spectrophotometer. Lyophilized DOX-loaded amphiphile aggregates were again dissolved in dimethyl sulfoxide (DMSO), and DOX mass concentration was evaluated according to a standard working curve. Thus, DOX loading content (DLC) and loading efficiency (DLE) were calculated in accordance with the following formulas [57].

$$
\begin{gathered}
\operatorname{DLC}(\text { wt } \%)=\frac{\text { Weight of loaded drug }}{\text { Weight of loaded drug and polymers }} \times 100 \% \\
\operatorname{DLE}(\%)=\frac{\text { Weight of loaded drug }}{\text { Weight of drug in feed }} \times 100 \%
\end{gathered}
$$




\subsection{Cell Viability Assay}

Cytotoxicity of the as-prepared PMAgala- $b$-PMAChol aggregates was evaluated with SK-Hep-1 cells and standard method of transcriptional and translational (MTT). SK-Hep-1 cells were first seeded into a 96-well microplate $\left(6 \times 10^{3}\right.$ cells/well) with Dulbecco's Modified Eagles Medium (DMEM) supplemented with $10 \%$ fetal bovine serum (FBS), and they were incubated for $24 \mathrm{~h}$. Then, the medium was aspirated and replaced with $100 \mu \mathrm{L}$ of fresh medium containing 10\% FBS, and it was supplemented with amphiphile aggregate solution under various mass concentration of 10, 30, 100, 300 , and $500 \mu \mathrm{g} / \mathrm{mL}$ and kept cultivation at $37^{\circ} \mathrm{C}$ under $5 \% \mathrm{CO}_{2}$ for another $24 \mathrm{~h}$. Afterwards, $20 \mu \mathrm{L}$ of MTT solution $(5.0 \mathrm{mg} / \mathrm{mL}$ ) was placed into the microplate, the medium was replaced with $100 \mu \mathrm{L}$ of FBS-free fresh medium and it was continuously incubated for $2 \mathrm{~h}$. Then, $100 \mu \mathrm{L}$ of DMSO was added into each well to dissolve the MTT-formazan, and light absorbances at $\lambda=490 \mathrm{~nm}$ were measured on a microplate reader (BioTek, ELX800, Winooski, VT, USA) with absorbances at $\lambda=630 \mathrm{~nm}$ as the reference. As a result, cell viability was evaluated in quintuplicate as follows:

$$
\text { Cell viability }(\%)=\left(\mathrm{OD}_{490}(\text { sample })-\mathrm{OD}_{630}(\text { sample) }) /\left(\mathrm{OD}_{490} \text { (control) }-\mathrm{OD}_{630}(\text { control) }) \times 100 \%\right. \text {. }\right.
$$

In a similar way, cell viability was examined for the PMAgala- $b$-PMAChol/DOX complex aggregates. After cell incubation for $24 \mathrm{~h}$, the medium was aspirated and replaced with $100 \mu \mathrm{L}$ of fresh medium (with 10\% FBS), and it was supplemented with predetermined amounts of DOX-loaded complex aggregates to give a series of final DOX mass concentration of 1, 2, 3, 5, 8, 10, and $15 \mu \mathrm{g} / \mathrm{mL}$. They were kept incubated at $37{ }^{\circ} \mathrm{C}$ under $5 \% \mathrm{CO}_{2}$ for $24 \mathrm{~h}$. Cell viability was accordingly evaluated as aforementioned.

\section{Results and Discussion}

\subsection{Synthesis and Characterization of the PMAgala-b-PMAChol Amphiphilic Copolymers}

As illustrated in Scheme 1, a new series of diblock PMAgala- $b$-PMAChol amphiphiles were prepared through sequential RAFT polymerization and successive TFA-mediated deprotection as we recently reported [52]. Figure $1 \mathrm{~A}$ shows a typical ${ }^{1} \mathrm{H}$ NMR spectrum for the as-resulted diblock PMAIpGP- $b$-PMAChol precursor, and the proton nuclei resonance signals were accordingly assigned $[41,58]$. In order to achieve final PMAgala $18-b$-PMAChol products, a reaction condition of TFA/dichloromethane $(1 / 2, v / v)$ at room temperature for $32 \mathrm{~h}$ was employed to deprotect the PMAIpGP 18 - $b$-PMAChol precursors, and a typical ${ }^{1} \mathrm{H}$ NMR spectrum recorded in pyridine- $d_{5}$ for the PMAgala 18 - $b$-PMAChol amphiphile is shown in Figure $1 \mathrm{~B}$, in which ${ }^{1} \mathrm{H}$ nuclei resonance signals attributable to each block were observed and accordingly assigned. Furthermore, GPC traces of the PMAIpGP macro-RAFT initiator and the series of diblock PMAIpGP- $b$-PMAChol precursors are presented in Figure 1C. The monodispersive and narrow molecular weight distribution demonstrated their well-defined polymer structures. To further substantiate the diblock amphiphile structures, oxygen elemental percentages were analyzed to be $23.43 \pm 0.11 \%, 18.95 \pm 0.03 \%$, $14.88 \pm 0.09 \%$, and $14.47 \pm 0.09 \%$ for the PMAgala $18-b-\mathrm{PMAChol}_{8}, \mathrm{PMAgala}_{18}-b-\mathrm{PMAChol}_{24}$, PMAgala $_{18}-b$-PMAChol 38 , and PMAgala $_{18}-b$-PMAChol 48 , respectively, and these values are very close to the theoretical oxygen elemental percentages of $25.71 \%, 18.24 \%, 14.94 \%$, and $13.92 \%$, respectively, as estimated on the basis of their corresponding PMAIpGP 18 - $b$-PMAChol precursors. As a result, the ${ }^{1} \mathrm{H}$ NMR and oxygen elemental analytical evidence could imply quantitative isopropylidene deprotection and sufficient structure stability of the diblock PMAgala 18 - $b$-PMAChols during deprotection. In this study, the synthetic results are summarized in Table 1. Notably, the synthesized PMAgala 18 - $b$-PMAChol amphiphiles have PMAChol block weight ratios of 50, 75, 83, and 86 wt \%, respectively. These amphiphiles with high hydrophobic block contents were designed for self-assembling into morphology-variable "crew-cut" aggregates, which may be employed as 
functional nanobiomaterial models for further elucidating the effects of glycopolymer structure and aggregate morphology on biomolecular recognition/adsorption and intracellular drug delivery.

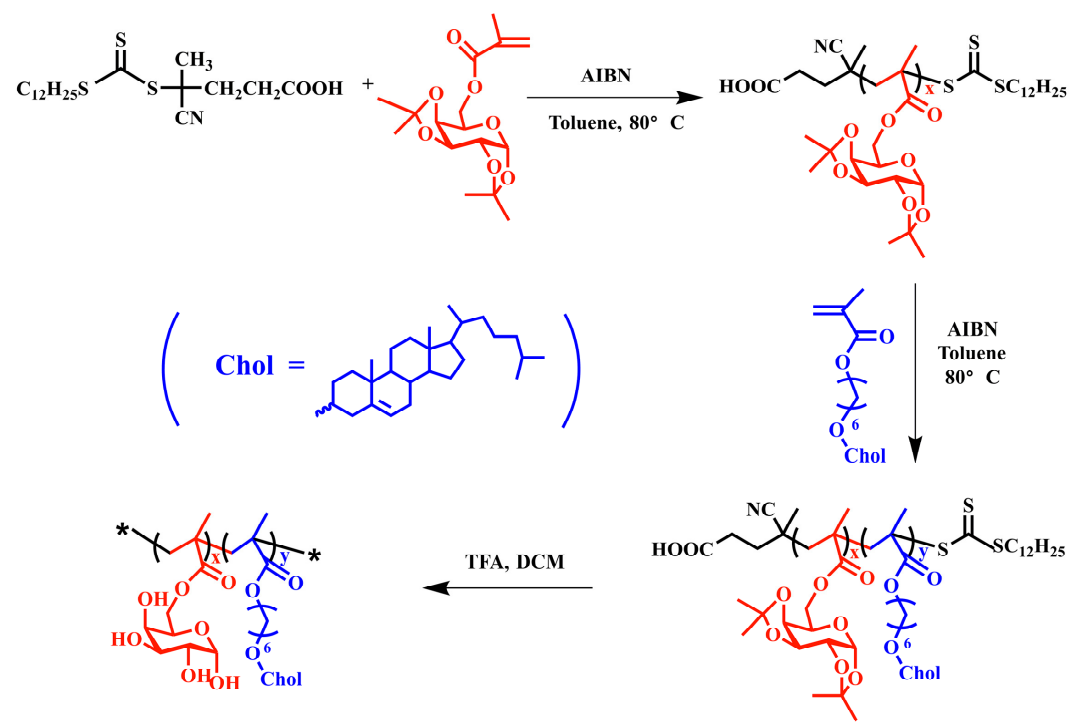

Scheme 1. Preparation of diblock poly(6-O-methacryloyl-D-galactopyranose)-b-poly(6-cholesteryloxyhexyl methacrylate) (PMAgala-b-PMAChol) amphiphiles bearing galactose and cholesterol grafts.

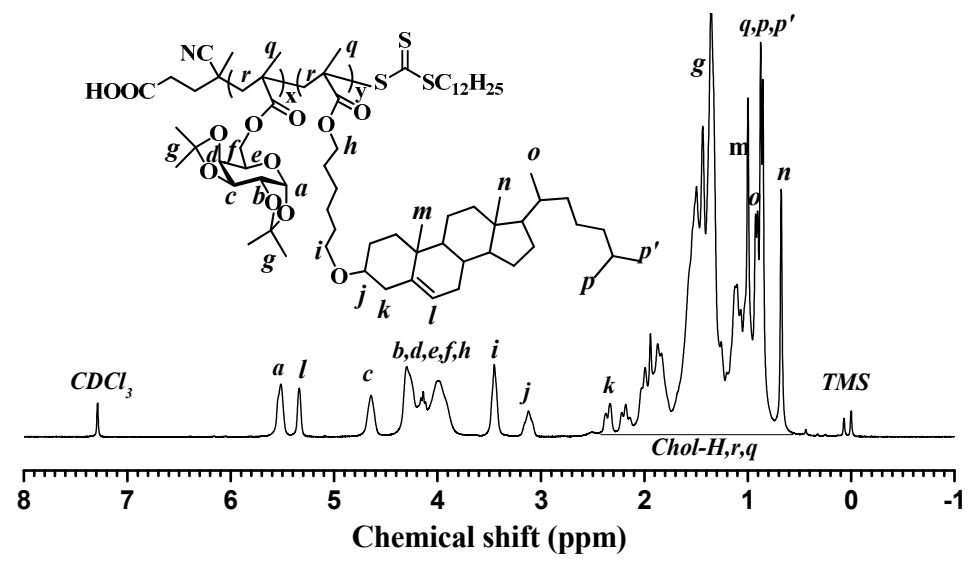

(a)

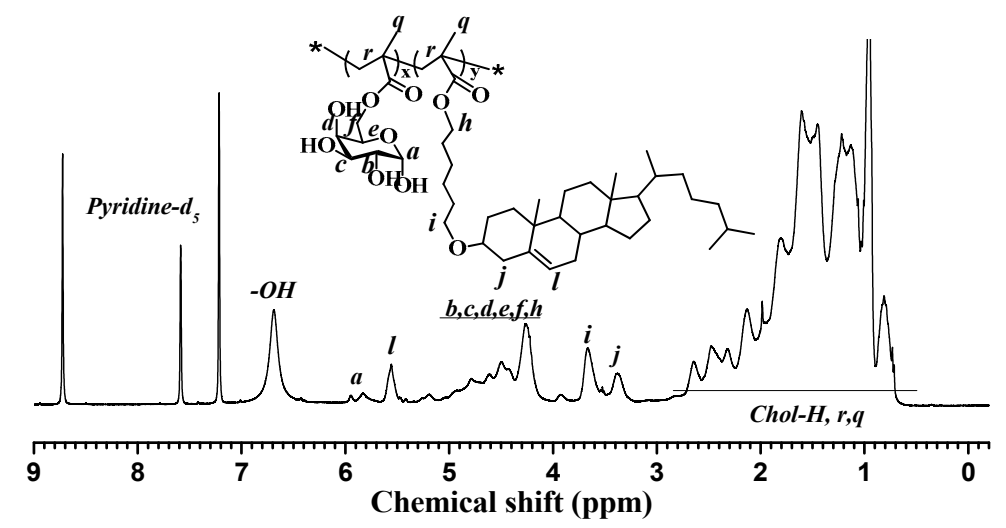

(b)

Figure 1. Cont. 


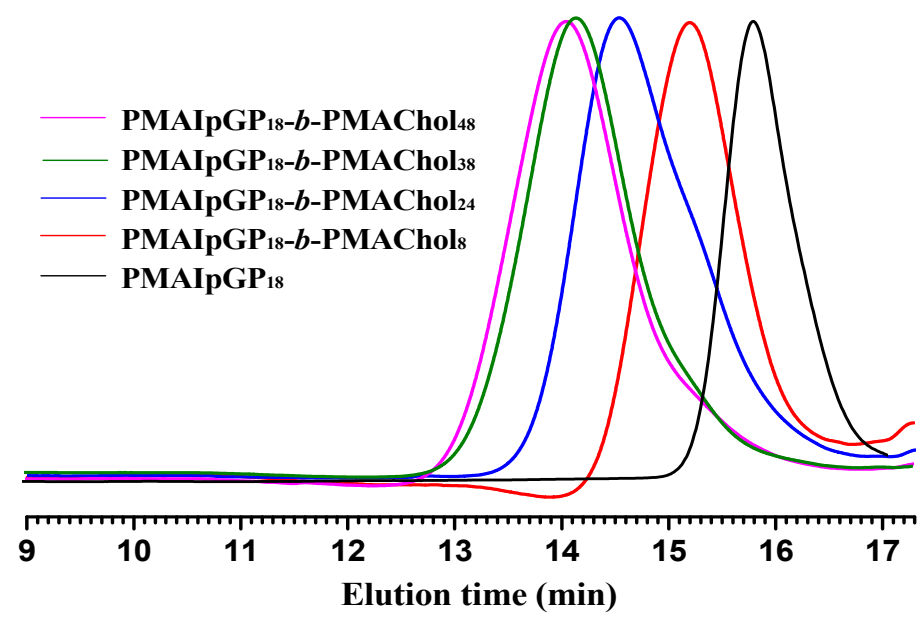

(c)

Figure 1. ${ }^{1} \mathrm{H}$ NMR spectra for the (a) synthesized diblock PMAIpGP- $b$-PMAChol in $\mathrm{CDCl}_{3}$; (b) PMAgala- $b$-PMAChol amphiphile in pyridine- $d_{5}$ and (c) Gel permeation chromatography (GPC) elution traces for the PMAIpGP 18 - $b$-PMAChol series along with the PMAIpGP 18 as macromolecular reversible addition-fragmentation chain transfer polymerization (macro-RAFT) initiator.

Table 1. Synthetic results for the PMAIpGP macro-RAFT initiator and diblock PMAIpGP-b-PMAChols.

\begin{tabular}{|c|c|c|c|c|c|c|c|}
\hline \multirow[b]{2}{*}{ Entry $^{1}$} & \multirow[b]{2}{*}{ Sample } & \multirow{2}{*}{$\begin{array}{c}\text { Monomer } \\
\text { Conversion (\%) }\end{array}$} & \multicolumn{4}{|c|}{ Molecular Weight } & \multirow{2}{*}{$\begin{array}{c}\text { PMAgala/PMAChol } \\
\text { Ratio (wt \%) }\end{array}$} \\
\hline & & & $\begin{array}{l}M_{\mathrm{n}, \text { thero }}{ }^{3} \\
\left(\mathrm{~kg} \mathrm{~mol}^{-1}\right)\end{array}$ & $\begin{array}{c}M_{\mathrm{w}, \mathrm{GPC}}{ }^{4} \\
\left(\mathrm{~kg} \mathrm{~mol}^{-1}\right)\end{array}$ & $\begin{array}{c}M_{\mathrm{n}, \mathrm{GPC}} \\
\left(\mathrm{kg} \mathrm{mol}^{-1}\right)\end{array}$ & $M_{\mathrm{w}} / M_{\mathrm{n}}{ }^{4}$ & \\
\hline 1 & PMAIpGP 18 & 91 & 6.37 & 5.56 & 4.95 & 1.10 & - \\
\hline 2 & $\begin{array}{l}\text { PMAIpGP }_{18}-b- \\
\text { PMAChol }_{8}\end{array}$ & 82 & 10.94 & 12.56 & 10.95 & 1.14 & $50 / 50$ \\
\hline 3 & $\begin{array}{l}\text { PMAIpGP }_{18}-b- \\
\text { PMAChol }_{24}\end{array}$ & 96 & 19.74 & 20.84 & 16.23 & 1.28 & $25 / 75$ \\
\hline 4 & $\begin{array}{l}\text { PMAIpGP }_{18}^{-b-} \\
\text { PMAChol }_{38}\end{array}$ & 96 & 27.76 & 19.83 & 24.74 & 1.23 & $17 / 83$ \\
\hline 5 & $\begin{array}{l}\text { PMAIpGP }_{18}-b- \\
\text { PMAChol }_{48}\end{array}$ & 95 & 32.83 & 36.19 & 31.23 & 1.15 & $14 / 86$ \\
\hline \multicolumn{8}{|c|}{ 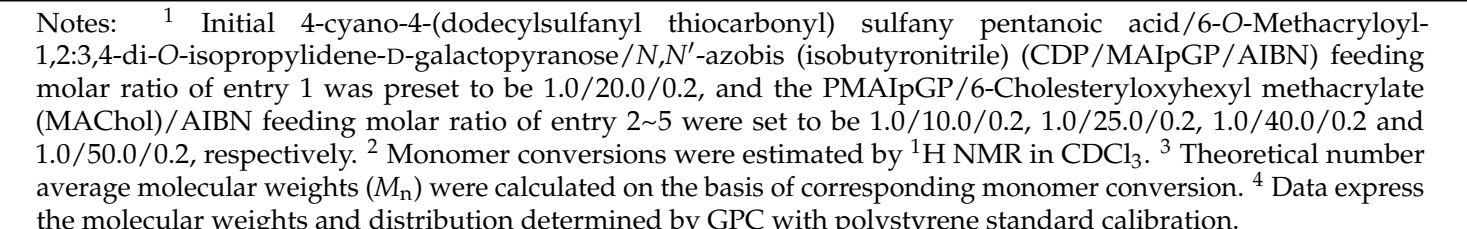 } \\
\hline
\end{tabular}

\subsection{Self-Assembly of the PMAgala-b-PMAChol Amphiphiles in Pyridine/Water Mixed Solvent}

To examine spontaneous aggregation, critical micelle concentration (CMC) of the PMAgala-b-PMAChol amphiphiles in pure water was first measured with a pyrene fluorescent probe (the results are shown in Figure S1). With an increase of PMAChol hydrophobic block length, the CMC values tend to decrease as the sequence of PMAgala 18 - $b$-PMAChol $8(6.82 \mathrm{mg} / \mathrm{L})>$ PMAgala $_{18}-b-$ PMAChol $_{24}(1.24 \mathrm{mg} / \mathrm{L})>$ PMAgala $_{18}$ - $b$-PMAChol 38 ( $\left.0.87 \mathrm{mg} / \mathrm{L}\right)>$ PMAgala $_{18}-b$-PMAChol ${ }_{48}(0.43 \mathrm{mg} / \mathrm{L})$. Lower CMC values suggest their self-assembled micelles may possess relatively higher stability in water. Furthermore, self-assembly of the PMAgala 18 - $b$-PMAChol amphiphilic copolymers were implemented via gradually dropping water into their pyridine solution at ambient temperature and continuous dialyzing against deionized water for $48 \mathrm{~h}$. Then, morphologies of the as-prepared aggregates under dry state were characterized by TEM. As shown in Figure 2, both PMAgala 18 -b-PMAChol 8 (50/50) and PMAgala ${ }_{18}$-b-PMAChol 48 $(14 / 86)$ amphiphiles self-assembled into spherical micelles with narrow nanoparticle size distribution. Their average aggregate diameters (d) under dry state determined by TEM were $\approx 51 \mathrm{~nm}$ and $423 \mathrm{~nm}$, respectively, a bit smaller than those as analyzed by DLS ( $\approx 92 \mathrm{~nm}$ and $543 \mathrm{~nm})$ in wet 
state (Figure S2) due to the micelle shrinkage upon dehydration for the TEM measurements. Notably, the PMAgala 18 - $b$-PMAChol ${ }_{24}(25 / 75)$ amphiphile spontaneously self-assembled into asymmetric nanofibrous aggregates with diameter sizes of $40 \sim 200 \mathrm{~nm}$ and several micrometers in length. In contrast, the PMAgala ${ }_{18}-b$-PMAChol 38 (17/83) amphiphile formed non-uniform nanoscopic spheres and fibers. To further investigate the self-assembly processes, turbidity diagrams of the mixed solution for the $\mathrm{PMAgala}_{18}-b-\mathrm{PMAChol}_{8}$ (red) and $\mathrm{PMAgala}_{18}-\mathrm{b}-\mathrm{PMAChol}_{24}$ (blue) were measured on a UV-vis spectrometer (Figure S3). Critical aggregation water contents (CWC) of $22.5 \%$ and $13.1 \%$ were further estimated for the PMAgala $18-b-\mathrm{PMAChol}_{8}(50 / 50)$ and PMAgala $18-b-\mathrm{PMAChol}_{24}$ (25/75) amphiphiles, respectively. This evidence inferred that the diblock amphiphiles with higher PMAChol hydrophobic ratios tend to have higher aggregation capability via their stronger hydrophobic interactions as the driving force in the pyridine/water solution. The equilibrium turbidities of the fibrous and spherical aggregate solution were evaluated to be 0.97 and 0.05 by UV-vis for the PMAgala $_{18}-b$-PMAChol 8 (50/50) and PMAgala 18 - $b$-PMAChol ${ }_{24}$ (25/75), respectively. It has been reported that the colloidal turbidity could give a semi-quantitative indication of the aggregate sizes [59], therefore, the results imply that the sizes for the PMAgala ${ }_{18}-b$-PMAChol ${ }_{24}$ nanofibers are larger than those of the $\mathrm{PMAgala}_{18}-b$-PMAChol 8 nanospheres.

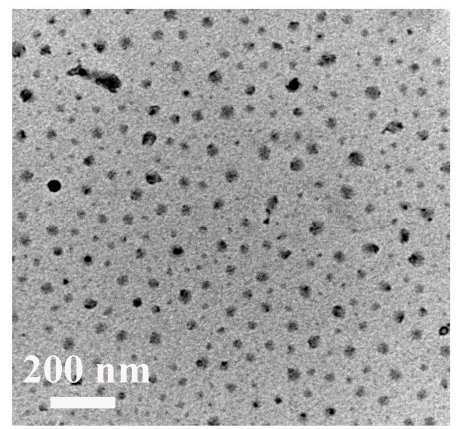

(a)

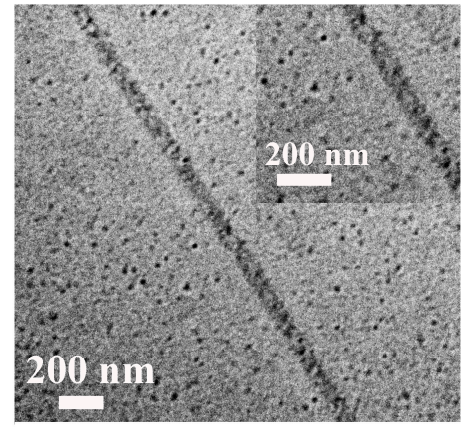

(c)

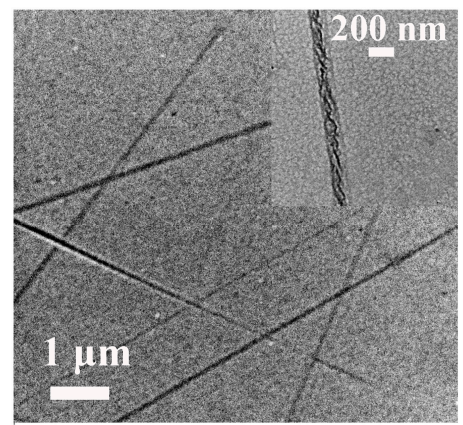

(b)

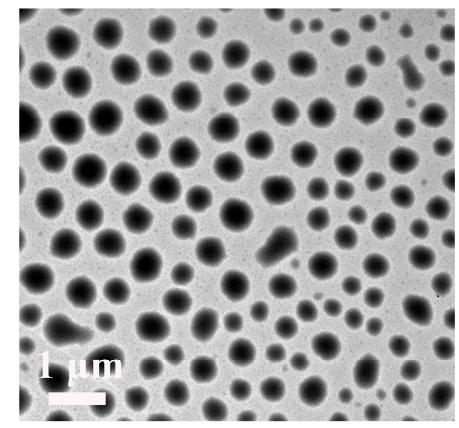

(d)

Figure 2. TEM morphologies of the series of amphiphile self-assemblies formed in pyridine/water mixed solution for the diblock PMAgala $18-b-$ PMAChol $_{8}$ (a); PMAgala $18-b$-PMAChol 24 (b); PMAgala $_{18}$-b-PMAChol 38 (c); and PMAgala 18 - $b$-PMAChol PM $_{48}(\mathbf{d})$.

\subsection{Lectin Recognition of the PMAgala-b-PMAChol Aggregates}

It is known that the specific interactions between carbohydrates and lectins play crucial roles in many biological processes like cell adhesion and hemagglutination. RCA 120 could specifically bind galactosyl residues. Con A exhibited high affinity to the glucosyl and mannosyl residues [60], and the binding efficiencies greatly depended on the molecular structure, sugar density, and morphology of 3D glycol-nanoparticles [14,61]. To further elucidate the roles of PMAgala- $b$-PMAChol polymer structures and related aggregate morphologies played on lectin recognition, turbidimetry was employed to assay the recognition between the as-prepared PMAgala- $b$-PMAChol aggregates and 
lectin $\mathrm{RCA}_{120}$. First, homopolymer PMAgala 18 was utilized as a model/control. As shown in Figure $3 \mathrm{~A}$, the PMAgala $18(0.1 \mathrm{mg} / \mathrm{mL})$ strongly interacted with the $\mathrm{RCA}_{120}$ and the light absorbance at $\lambda=450 \mathrm{~nm}$ enhanced along with the increase of lectin concentration from $0.1 \mathrm{mg} / \mathrm{mL}$ to $0.8 \mathrm{mg} / \mathrm{mL}$. In contrast, no significant change could be observed in the presence of Con A or BSA, demonstrating specific recognition interaction occurred between the PMAgala 18 and lectin $\mathrm{RCA}_{120}$. As for the self-assembled aggregates solution, the $\mathrm{PMAgala}_{18}-\mathrm{b}$-PMAChol $\mathrm{PM}_{8}$ sperical aggregate $(\mathrm{d} \approx 92 \mathrm{~nm})$ solution showed the highest light absorbance while the PMAgala $18-b$-PMAChol ${ }_{24}$ fibrous aggregate solution exhibited the lowest light absorbance under an RCA 120 mass concentration of $0.2 \mathrm{mg} / \mathrm{mL}$ (Figure 3B) and $0.5 \mathrm{mg} / \mathrm{mL}$ (Figure 3C). Figure S4 depicts the pictures of the PMAgala $18-b-\mathrm{PMAChol}_{8}$ and $\mathrm{PMAgala}_{18}-b$-PMAChol 24 aggregate solution before and after adding the $\mathrm{RCA}_{120}$. Aqueous solution with the PMAgala $18-b$-PMAChol ${ }_{8}$ spherical aggregates turned turbid with the formation of cotton-like aggregates upon the addition of lectin, furthermore, quite different particle sizes of the PMAgala $18-b$-PMAChol 48 aggregates were also detected by DLS. The results suggested that the lectin $\mathrm{RCA}_{120}$ recognition capabilities of the PMAgala 18 - $b$-PMAChol aggregates largely relied on their 3D-morphologies. Kim et al. [62] previously reported that glycol-containing nanospheres with higher curvature $(\mathrm{d} \approx 12 \mathrm{~nm})$ have stronger binding to Con $A$ than that of the vesicular $(\mathrm{d} \approx 40 \mathrm{~nm})$ and cylindrical objects, whilst Ladmira et al. [7] disclosed that the galactose functionalized vesicles exhibited much stronger and faster optical response upon the exposure to $\mathrm{RCA}_{120}$ than that of the worm-like micelles and spheres. In addition, Huang et al. [11] found that in the presence of $\mathrm{RCA}_{120}$, the glycopeptides with longer blocks in aqueous solution showed higher light absorbance at $\lambda=450 \mathrm{~nm}$, nevertheless, the exact reason of the copolymer chain length and the self-assemblies structure was thereby uncertain. In this study, the results of lectin recognition in aqueous solution for the PMAgala ${ }_{18}$ and series of PMAgala ${ }_{18}$ - $b$-PMAChols aggregates with the same PMAgala 18 block ratios could undoubtedly guarantee the polymer structure and aggregate morphology, predominantly influencing the recognition between the PMAgala 18 - $b$-PMAChol aggregates and lectin; this may benefit the development of new galactose-based biomaterials for lectin detection and separation.

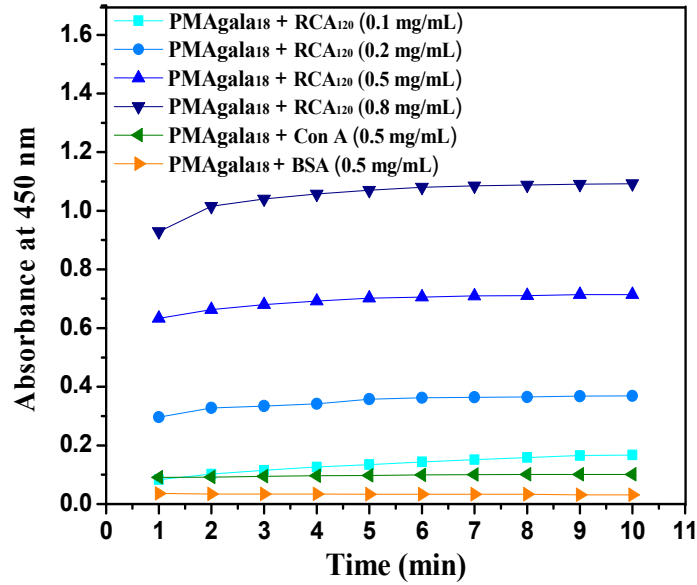

(a)

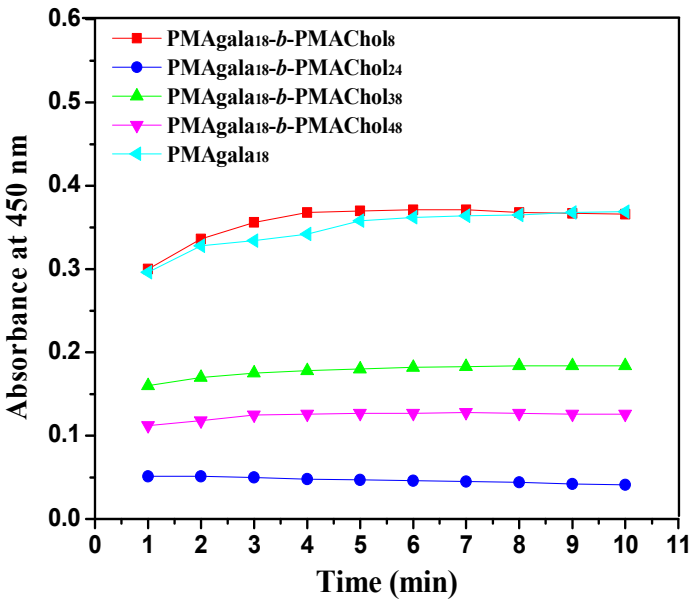

(b)

Figure 3. Cont. 


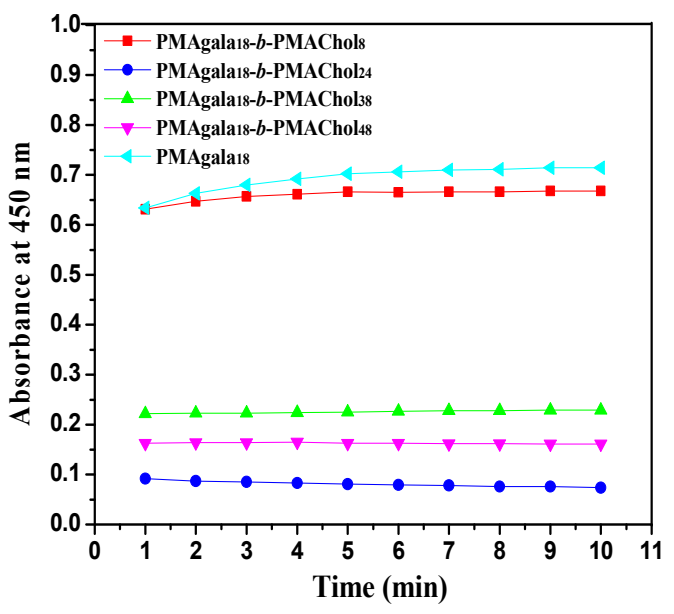

(c)

Figure 3. Light absorbance of aqueous solution at $\lambda=450 \mathrm{~nm}$ for the PMAgala $18(0.1 \mathrm{mg} / \mathrm{mL})$ in the presence of ricinus communis agglutinin II ( $\left.\mathrm{RCA}_{120}\right)$ (various concentrations), Concanavalin A from Canavalia ensiformis (Con A) $(0.5 \mathrm{mg} / \mathrm{mL})$, and bovine serum albumin (BSA) $(0.5 \mathrm{mg} / \mathrm{mL})(\mathbf{a})$ and the interactions between PMAgala 18 - $b$-PMAChol self-assemblies $(0.1 \mathrm{mg} / \mathrm{mL}$ for the PMAgala block) with $\mathrm{RCA}_{120}$ under $0.2 \mathrm{mg} / \mathrm{mL}$ (b) and $0.5 \mathrm{mg} / \mathrm{mL}$ (c).

\subsection{Serum Protein Adsorption of the PMAgala-b-PMAChol Aggregates}

So far, the adsorption of serum proteins on synthetic nanoparticle surfaces has been known to significantly affect particle internalization and pharmacokinetics, and the nanoparticle composition, size, curvature, surface potential, and hydrophobicity largely influence its protein binding profile [63]. Therefore, the design of functional nanoparticles with less serum protein adsorption seems important for realizing prolonged blood circulation in vivo. In this study, bovine serum albumin (BSA) was taken as a model protein to examine the effect of PMAgala ${ }_{18}-b$-PMAChol aggregate morphology on protein adsorption in aqueous solution. Figure 4 depicts the results of BSA adsorption assay by UV-vis. The water-soluble PMAgala 18 and PMAgala ${ }_{18}-b$-PMAChol ${ }_{8}$ spherical aggregates $(\mathrm{d} \approx 92 \mathrm{~nm})$ under $0.5 \mathrm{mg} / \mathrm{mL}$ showed very low BSA adsorption, only $4.6 \%$ and $8.8 \%$ BSA were adsorbed within $5 \mathrm{~h}$, much lower than that of PEG-5K negative control (19.8\% BSA for $5 \mathrm{~h}$ ). In comparison, the fibrous PMAgala ${ }_{18}-b$-PMAChol ${ }_{24}$ aggregates under $0.5 \mathrm{mg} / \mathrm{mL}$ gave the highest BSA adsorption, with $28.8 \%$ and $32.6 \%$ BSA adsorption after $3 \mathrm{~h}$ and $5 \mathrm{~h}$ incubation, respectively, far below that of the PEI-25K positive control $(90.0 \%$ and $92.0 \%$, respectively) due to negative surface charge of the glycol-nanoparticles [64]. Intriguingly, the different BSA adsorption for the PMAgala 18 - $b$-PMAChol aggregates may be interpreted as due to their much more distinct aggregate morphologies on lectin recognition, as discussed above. Comparing to the fibrous aggregates, the PMAgala ${ }_{18}-b$-PMAChol 8 spherical aggregates with lower BSA binding affinities were expected to be employed as high efficient serum-resistance drug carriers for therapeutic application. 


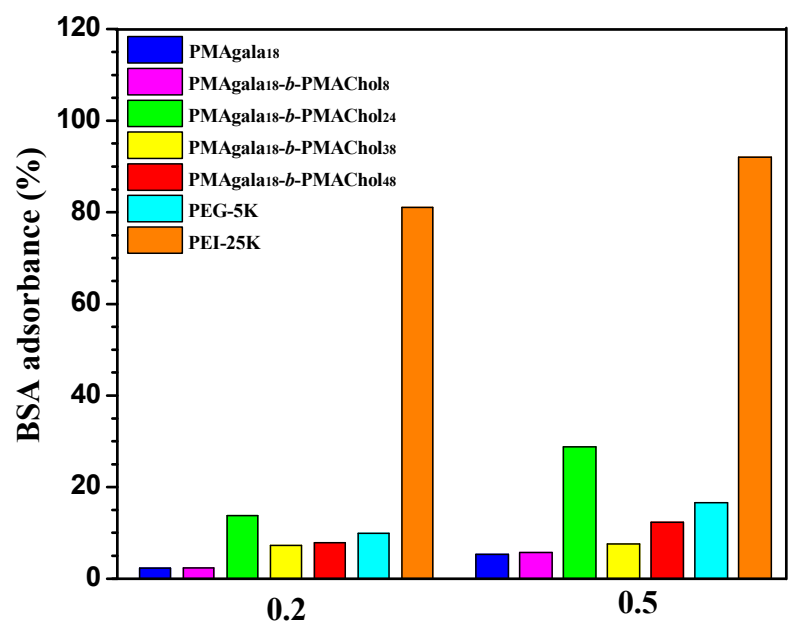

Polymer mass concentration $(\mathbf{m g} / \mathbf{m L})$

(a)

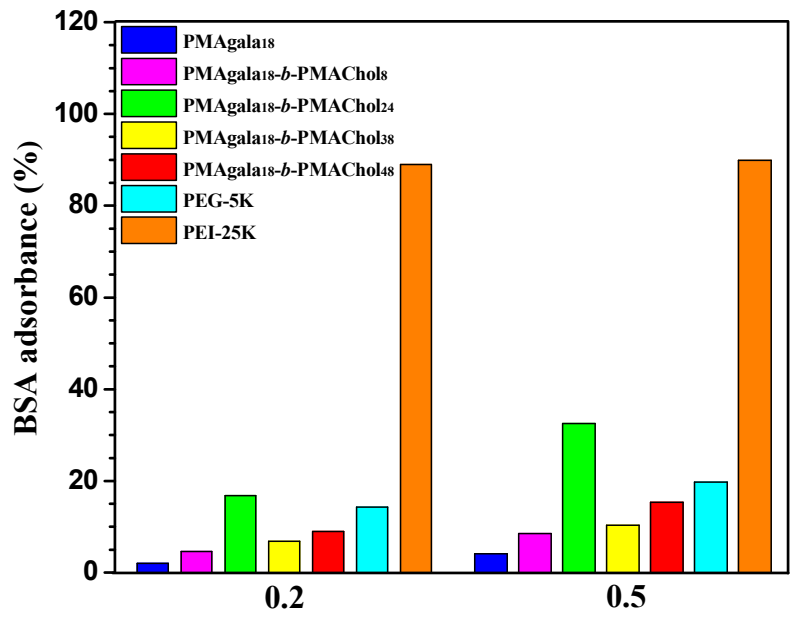

Polymer mass concentration $(\mathrm{mg} / \mathrm{mL})$

(b)

Figure 4. BSA adsorption assay for the PMAgala 18 and PMAgala $_{18}-b$-PMAChol aggregates under $37^{\circ} \mathrm{C}$ in aqueous solution for an incubation of $3 \mathrm{~h}(\mathbf{a})$ and $5 \mathrm{~h}(\mathbf{b})$. Poly(ethylene glycol) with a molecular weight of $5000 \mathrm{Da}$ (PEG-5K) and branched polyethylenimine with molecular weight of 25,000 Da (PEI-25K) were employed as the negative and positive controls, respectively. BSA protein mass concentration was preset to be $0.5 \mathrm{mg} / \mathrm{mL}$.

\subsection{Intracellular Doxorubicin (DOX) Delivery by the PMAgala $18^{-b}$-PMAChol/DOX Complex Aggregates}

To further exploit the above-synthesized PMAgala ${ }_{18}-b$-PMAChols as drug delivery carriers, the cell toxicities were firstly evaluated by MTT assay with SK-Hep-1 cells, the results are shown in Figure 5. Under a PMAgala 18 -b-PMAChol concentration up to $500 \mu \mathrm{g} / \mathrm{mL}$, SK-Hep-1 cell viabilities were observed higher than $90 \%$, indicating their very low cytotoxicities in vitro. By using DOX as an anti-tumor model drug, the DOX-loaded complex aggregates PMAgala ${ }_{18}-b$-PMAChols/DOX were prepared by nanoprecipitation in pyridine/water solution, similar to the preparation condition of the above-mentioned PMAgala 18 - $b$-PMAChol aggregates. As shown in Table S1, the DLCs were measured as $8.71 \mathrm{wt} \%$ (PMAgala $\left.18-b-\mathrm{PMAChol}_{8}\right), 7.75$ wt \% (PMAgala $18-b$-PMAChol 24 ), 8.26 wt \% (PMAgala $18-b-$ PMAChol $\left._{38}\right)$, and 9.33 wt \% (PMAgala $18-b-$ PMAChol $\left._{48}\right)$, and the corresponding DLEs were calculated to be $85.9 \%, 75.6 \%, 81.0 \%$, and $92.6 \%$, respectively. Morphologies of the PMAgala 18 - $b$-PMAChol/DOX complex aggregates were investigated by TEM 
(Figure 6), and the self-assembled aggregates with various aggregate morphologies including nanospheres (PMAgala ${ }_{18}-b$-PMAChol $8 / \mathrm{DOX}$ ), nanofibers (PMAgala ${ }_{18}-b-\mathrm{PMAChol}_{24} / \mathrm{DOX}$ ), mixture of nanospheres/nanofibers (PMAgala ${ }_{18}-b$-PMAChol $38 / \mathrm{DOX}$ ), and nanospindles (PMAgala ${ }_{18}-b-$ $\left.\mathrm{PMAChol}_{48} / \mathrm{DOX}\right)$ were observed, indicating the DOX-loaded morphology-variable aggregates could be obtained by using the certain amphiphilic glycopolymer as the drug carrier. To study the DOX delivery efficiency of the as-prepared morphology-variable aggregates, SK-Hep-1 cell viabilities were examined by MTT assay. It could be seen that the tumor cell proliferation inhibition strongly depended on DOX dosage, and cell viabilities decreased to $45 \sim 63 \%$ under the DOX dosage of $15 \mu \mathrm{g} / \mathrm{mL}$ (Figure 7), inferring efficient endocytosis and intracellular DOX release of the DOX-loaded complex aggregates. Noteworthy, the SK-Hep-1 cell proliferation greatly depended on the morphologies of the complex aggregates, the spherical complex aggregates (PMAgala 18 - $b$-PMAChol 8 /DOX) showed the highest cell proliferation inhibition efficiency, whilst the nanofibrous aggregates (PMAgala ${ }_{18}-b$-PMAChol $24 / \mathrm{DOX}$ ) exhibited the lowest cell inhibition under the same DOX dosage. Moreover, the $\mathrm{IC}_{50}$ (half maximal inhibitory concentration) values were evaluated to be $9.06,26.70,13.54$, and $14.36 \mu \mathrm{g}$ DOX equiv./ $\mathrm{mL}$ for the above complex aggregates, respectively. The results may due to their different molecular structure/morphology-dependent cellular interactions and drug release; the spherical complex aggregates have comparably smaller size and larger surface area than the aggregates with other morphologies, which may endow them with their higher cellular uptake and drug release manners. Likewise, Zheng et al. [65] reported that drug release behavior was determined by the matrix morphologies and the interactions between drug and matrix, and the methoxy poly(ethyleneglycol)-poly(lactic acid) (mPEG-PLA) nanofibrous vectors showed BSA release slower than that of their nanoparticle counterparts with corresponding kinetic $t_{1 / 2}$ (time for $50 \%$ drug release) of $175.5 \mathrm{~h}$ and $11.76 \mathrm{~h}$, respectively. Alternatively, methotrexate (MTX) decorated MPEG-PLA nanobacillus (MPEG-PLA-MTX NB) prepared by Hou et al [35] were shown to enhance cell internalization, accumulation, and tumor inhibition superiorly to that of the MPEG-PLA-MTX spherical nanoparticles in vivo. In addition, the $\mathrm{IC}_{50}$ values of a series of poly[oligo(ethyleneglycol) methacrylate]-block-[poly(styrene)-co-poly(vinyl benzaldehyde)] (POEGMA-b-P(ST-co-VBA)-DOX) nanoparticles with distinct morphologies were found to decrease in an order from micelles, vesicles, rods to worm-like nanoparticles with MCF-7 breast cancer cells [34]. In fact, until now, there was a lack of in-depth studies for revealing the morphological effects of nanoscale drug carriers on their interaction with cells and subsequent intracellular trafficking and drug release. In this work, the preliminary study on PMAgala $18^{-}-b$-PMAChols/DOX complex aggregates as drug carriers demonstrated an obvious molecular structure/morphology-dependent intracellular DOX release and tumor cell proliferation inhibition, which may provide potential platforms for designing highly efficient drug delivery nanosystems. 


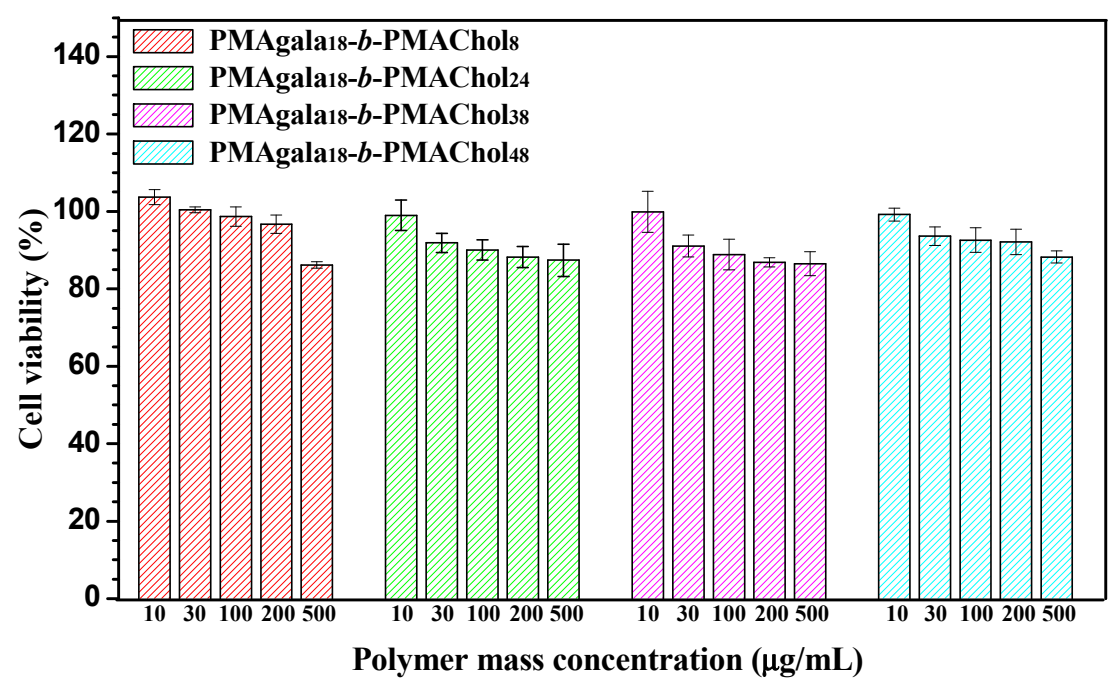

Figure 5. Cell viability assay for the series of PMAgala $18^{-}-b$-PMAChol aggregates with SK-Hep-1 cells after $24 \mathrm{~h}$ incubation. Data were presented as the average with standard deviation $(n=5)$.

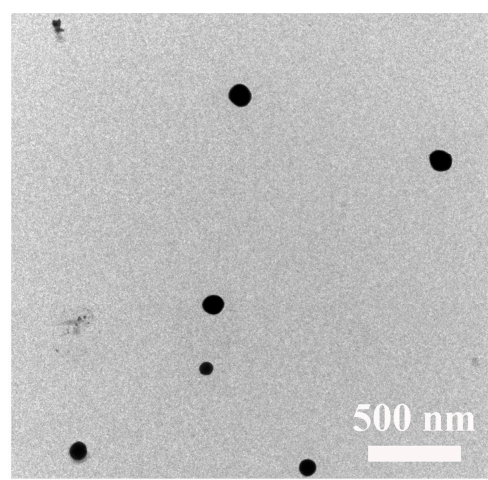

(a)

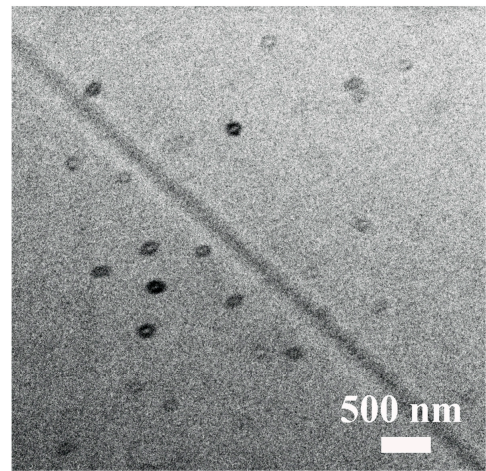

(c)

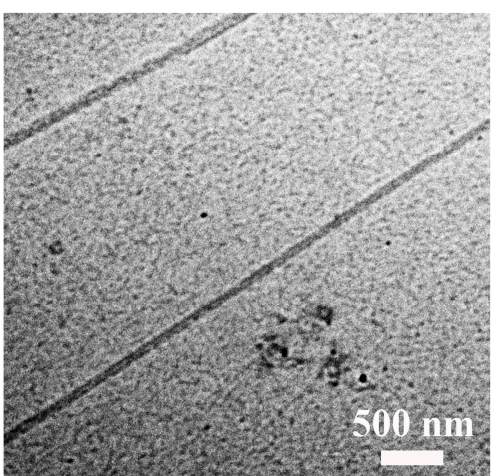

(b)

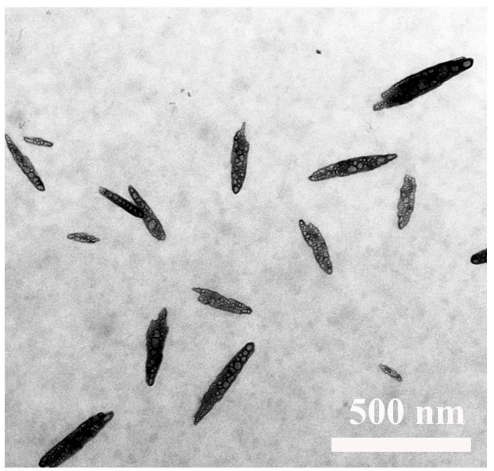

(d)

Figure 6. TEM morphologies for the doxorubicin (DOX)-loaded complex aggregates for the PMAgala $_{18}$-b-PMAChol 8 (a); PMAgala $_{18}-b$-PMAChol 24 (b); PMAgala $_{18}-b$-PMAChol 38 (c); and PMAgala $_{18}$ - $b$-PMAChol 48 (d). 


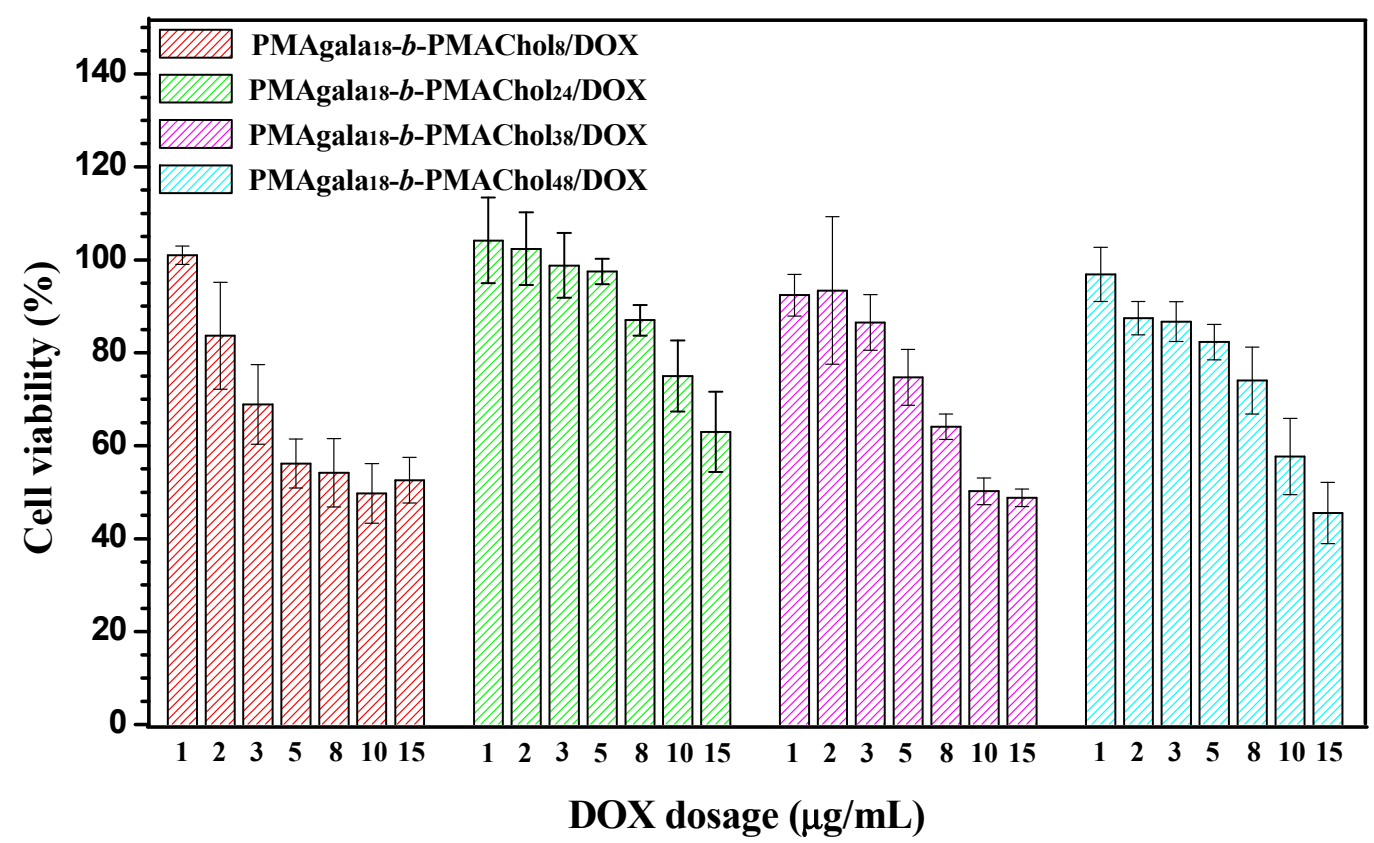

Figure 7. Cell viability assay for the DOX-loaded complex aggregates with SK-Hep-1 cells after $24 \mathrm{~h}$ incubation.

\section{Conclusions}

In summary, a new series of diblock PMAgala 18 - $b$-PMAChol amphiphilic glycopolymers with galactose and cholesterol grafts were designed and prepared. These glycopolymers could self-assemble into morphology-variable nanoscale aggregates from spherical nanoparticles to nanofibers. These glycol-containing amphiphilic aggregates showed different lectin $\mathrm{RCA}_{120}$ recognition and BSA adsorption behaviors, largely relying on their molecular structure/aggregate morphology. MTT assay of the PMAgala 18 - $b$-PMAChol aggregates (up to $500 \mu \mathrm{g} / \mathrm{mL}$ ) indicated their low cytotoxicity toward SK-Hep-1 cells, enabling them to serve as promising drug carriers in vivo. Furthermore, the PMAgala 18 - $b$-PMAChol/DOX complex aggregates were prepared, and the DOX-loading and cell proliferation inhibition properties of the complex aggregates were also found to be molecular structure/morphology-dependent. The spherical complex aggregates gave rise to higher tumor cell inhibition efficiency than those of the nanofibrous and nanospindles counterparts under the same DOX dosages. The study may provide a potential molecular structure/morphology-control approach towards the design and preparation of efficient amphiphilic glycopolymers for protein recognition/adsorption and drug delivery.

Supplementary Materials: The following are available online at http:/ /www.mdpi.com/2079-4991/8/3/136/s1. Figure S1: Fluorescence intensity ratios (I394/I374) as a function of logarithm of PMAgala $18-b$-PMAChol mass concentration in water. Figure S2: Particle sizes and distributions for the amphiphile self-assemblies formed by diblock PMAgala 18 - $b$-PMAChol 8 and PMAgala $18-b$-PMAChol 48 by DLS $(\mathrm{A}, \mathrm{C})$ and TEM (B,D), respectively. Figure S3: Turbidity profiles for the $\mathrm{PMAgala}_{18}-b-\mathrm{PMAChol}_{8}(\mathrm{~A})$ and $\mathrm{PMAgala}_{18}-b$-PMAChol ${ }_{24}$ (B) in pyridine/water mixed solution with initial mass concentration of $3.0 \mathrm{mg} / \mathrm{mL}$ in pyridine, and the inset demonstrated the photograph of amphiphile aggregate solutions for the PMAgala $18-b$-PMAChol ${ }_{8}$ (A) and PMAgala $_{18}-b-\mathrm{PMAChol}_{24}$ (B). Figure S4: Photographs of the PMAgala $18-b-\mathrm{PMAChol}_{8}(\mathrm{~A}, \mathrm{~B})$ and $\mathrm{PMAgala}_{18}-b-\mathrm{PMAChol}_{24}(\mathrm{C}, \mathrm{D})$ aggregate solutions before and after adding $\mathrm{RCA}_{120}$. Particle sizes and distributions were analyzed by DLS for the PMAgala $18-b$-PMAChol 8 self-assemblies in the absence (blue curve) and the presence (red curve) of $\mathrm{RCA}_{120}$ (E). Table S1: Characteristics of the doxorubicin (DOX)-loaded complex nanoparticles by diblock PMAgala $_{18}$ - $b$-PMAChol amphiphiles.

Acknowledgments: The authors are indebted to the funding support from the National Natural Science Foundation of China (No. 21504050, 21174160 and 21372251), sponsorship by the Shanghai Pujiang Program (No. 15PJ1402400) and Research Foundation of Key Laboratory of Synthetic and Self-Assembly Chemistry for Organic Functional Molecules of SIOC (No. K2016-1). Ruilong Sheng appreciates the 
ARDITI-Agência Regional para o Desenvolvimento da Investigação Tecnologia e Inovação through the project M1420-01-0145-FEDER-000005-Centro de Química da Madeira-CQQM+ (Madeira 14-20) for sponsorship.

Author Contributions: Z.W., R.S., A.C., and L.J. conceived and designed the experiments; Z.W. and T.L. performed the experiments; Z.W., R.S., J.S. and L.J. analyzed the data; R.S. and A.C. contributed reagents/materials/analysis tools; Z.W., R.S., A.C. and L.J. wrote the paper.

Conflicts of Interest: The authors declare no conflict of interest.

\section{References}

1. Delbianco, M.; Bharate, P.; Varela-Aramburu, S.; Seeberger, P.H. Glycopolymer Nanobiotechnology. Chem. Rev. 2016, 116, 1693-1752. [CrossRef] [PubMed]

2. Sun, J.; Sheng, R.; Luo, T.; Wang, Z.; Li, H.; Cao, A. Synthesis of diblock/statistical cationic glycopolymers with pendant galactose and lysine moieties: Gene delivery application and intracellular behaviors. J. Mater. Chem. B 2016, 4, 4696-4706. [CrossRef]

3. Wang, Z.; Sheng, R.; Luo, T.; Sun, J.; Cao, A. Synthesis and self-assembly of diblock glycopolypeptide analogues PMAgala- $b$-PBLG as multifunctional biomaterials for protein recognition, drug delivery and hepatoma cell targeting. Polym. Chem. 2017, 8, 472-484. [CrossRef]

4. Von der Ehe, C.; Weber, C.; Gottschaldt, M.; Schubert, U.S. Immobilized glycopolymers: Synthesis, methods and applications. Prog. Polym. Sci. 2016, 57, 64-102. [CrossRef]

5. Li, Z.; Liang, Y.; Li, F. Multiple morphologies of aggregates from block copolymers containing glycopolymer segments. Chem. Commun. 1999, 16, 1557-1558. [CrossRef]

6. Pati, D.; Das, S.; Patil, N.G.; Parekh, N.; Anjum, D.H.; Dhaware, V.; Ambade, A.V.; Sen Gupta, S. Glycopolypeptide-based amphiphilic biocompatible star copolymers and their carbohydrate specific intracellular delivery. Biomacromolecules 2016, 17, 466-475. [CrossRef] [PubMed]

7. Ladmiral, V.; Semsarilar, M.; Canton, I.; Armes, S.P. Polymerization-induced self-assembly of galactose-functionalized biocompatible diblock copolymers for intracellular delivery. J. Am. Chem. Soc. 2013, 135, 13574-13581. [CrossRef] [PubMed]

8. Su, L.; Wang, C.; Polzer, F.; Lu, Y.; Chen, G.; Jiang, M. Glyco-inside micelles and vesicles directed by protection-deprotection chemistry. ACS Macro Lett. 2014, 3, 534-539. [CrossRef]

9. Wu, X.; Su, L.; Chen, G.; Jiang, M. Deprotection-induced micellization of glycopolymers: Control of kinetics and morphologies. Macromolecules 2015, 48, 3705-3712. [CrossRef]

10. Schlaad, H.; You, L.; Sigel, R.; Smarsly, B.; Heydenreich, M.; Mantion, A.; Masić, A. Glycopolymer vesicles with an asymmetric membrane. Chem. Commun. 2009, 1, 1478-1480. [CrossRef] [PubMed]

11. Huang, J.; Bonduelle, C.; Thévenot, J.; Lecommandoux, S.; Heise, A. Biologically active polymersomes from amphiphilic glycopeptides. J. Am. Chem. Soc. 2012, 134, 119-122. [CrossRef] [PubMed]

12. Zeng, X.; Qu, K.; Rehman, A. Glycosylated conductive polymer: A multimodal biointerface for studying carbohydrate-protein interactions. Acc. Chem. Res. 2016, 49, 1624-1633. [CrossRef] [PubMed]

13. Sakai, F.; Yang, G.; Weiss, M.S.; Liu, Y.; Chen, G.; Jiang, M. Protein crystalline frameworks with controllable interpenetration directed by dual supramolecular interactions. Nat. Commun. 2014, 5, 4634. [CrossRef] [PubMed]

14. Wei, K.; Li, J.; Chen, G.; Jiang, M. Dual molecular recognition leading to a protein-polymer conjugate and further self-assembly. ACS Macro Lett. 2013, 2, 278-283. [CrossRef]

15. Reynhout, I.C.; Cornelissen, J.J.L.M.; Nolte, R.J.M. Synthesis of polymer-biohybrids: From small to giant surfactants. Acc. Chem. Res. 2009, 42, 681-692. [CrossRef] [PubMed]

16. Yamanaka, M.; Haraya, N.; Yamamichi, S. Chemical stimuli-responsive supramolecular hydrogel from amphiphilic tris-urea. Chem. Asian J. 2011, 6, 1022-1025. [CrossRef] [PubMed]

17. Ting, S.R.S.; Chen, G.; Stenzel, M.H. Synthesis of glycopolymers and their multivalent recognitions with lectins. Polym. Chem. 2010, 1, 1392-1412. [CrossRef]

18. Lu, J.; Fu, C.; Wang, S.; Tao, L.; Yan, L.; Haddleton, D.M.; Chen, G.; Wei, Y. From polymer sequence control to protein recognition: Synthesis, self-assembly and lectin binding. Macromolecules 2014, 47, 4676-4683. [CrossRef] 
19. Liau, W.T.; Bonduelle, C.; Brochet, M.; Lecommandoux, S.; Kasko, A.M. Synthesis, characterization, and biological interaction of glyconanoparticles with controlled branching. Biomacromolecules 2015, 16, 284-294. [CrossRef] [PubMed]

20. Ma, Z.; Jia, Y.G.; Zhu, X. Glycopolymers bearing galactose and betulin: Synthesis, encapsulation, and lectin recognition. Biomacromolecules 2017, 18, 3812-3818. [CrossRef] [PubMed]

21. Wang, B.; He, X.; Zhang, Z.; Zhao, Y.; Feng, W. Metabolism of nanomaterials in vivo: Blood circulation and organ clearance. Acc. Chem. Res. 2013, 46, 761-769. [CrossRef] [PubMed]

22. Duan, X.; Li, Y. Physicochemical characteristics of nanoparticles affect circulation, biodistribution, cellular internalization, and trafficking. Small 2013, 9, 1521-1532. [CrossRef] [PubMed]

23. Banerjee, A.; Qi, J.; Gogoi, R.; Wong, J.; Mitragotri, S. Role of nanoparticle size, shape and surface chemistry in oral drug delivery. J. Control. Release 2016, 238, 176-185. [CrossRef] [PubMed]

24. Toy, R.; Peiris, P.M.; Ghaghada, K.B.; Karathanasis, E. Shaping cancer nanomedicine: The effect of particle shape on the in vivo journey of nanoparticles. Nanomedicine 2014, 9, 121-134. [CrossRef] [PubMed]

25. Liu, Y.; Tan, J.; Thomas, A.; OuYang, D.; Muzykantov, V.R. The shape of things to come: Importance of design in nanotechnology for drug delivery. Ther. Deliv. 2012, 3, 181-194. [CrossRef] [PubMed]

26. Williford, J.-M.; Santos, J.L.; Shyam, R.; Mao, H.Q. Shape control in engineering of polymeric nanoparticles for therapeutic delivery. Biomater. Sci. 2015, 3, 894-907. [CrossRef] [PubMed]

27. Truong, N.P.; Whittaker, M.R.; Mak, C.W.; Davis, T.P. The importance of nanoparticle shape in cancer drug delivery. Expert Opin. Drug Deliv. 2015, 12, 129-142. [CrossRef] [PubMed]

28. Champion, J.A.; Mitragotri, S. Role of target geometry in phagocytosis. Proc. Natl. Acad. Sci. USA 2006, 103, 4930-4934. [CrossRef] [PubMed]

29. Hu, X.; Hu, J.; Tian, J.; Ge, Z.; Zhang, G.; Luo, K.; Liu, S. Polyprodrug amphiphiles: Hierarchical assemblies for shape-regulated cellular internalization, trafficking, and drug delivery. J. Am. Chem. Soc. 2013, 135, 17617-17629. [CrossRef] [PubMed]

30. Elsabahy, M.; Shrestha, R.; Clark, C.; Taylor, S.; Leonard, J.; Wooley, K.L. Multifunctional hierarchically assembled nanostructures as complex stage-wise dual-delivery systems for coincidental yet differential trafficking of siRNA and paclitaxel. Nano Lett. 2013, 13, 2172-2181. [CrossRef] [PubMed]

31. Jiang, X.; Qu, W.; Pan, D.; Ren, Y.; Williford, J.-M.M.; Cui, H.; Luijten, E.; Mao, H. Plasmid-templated shape control of condensed DNA-block copolymer nanoparticles. Adv. Mater. 2013, 25, 227-232. [CrossRef] [PubMed]

32. Geng, Y.; Dalhaimer, P.; Cai, S.; Tsai, R.; Tewari, M.; Minko, T.; Discher, D.E. Shape effects of filaments versus spherical particles in flow and drug delivery. Nat. Nanotechnol. 2007, 2, 249-255. [CrossRef] [PubMed]

33. Beniash, E.; Hartgerink, J.D.; Storrie, H.; Stendahl, J.C.; Stupp, S.I. Self-assembling peptide amphiphile nanofiber matrices for cell entrapment. Acta Biomater. 2005, 1, 387-397. [CrossRef] [PubMed]

34. Karagoz, B.; Esser, L.; Duong, H.T.; Basuki, J.S.; Boyer, C.; Davis, T.P. Polymerization-induced self-assembly (PISA)-control over the morphology of nanoparticles for drug delivery applications. Polym. Chem. 2014, 5, 350-355. [CrossRef]

35. Cui, F.; Lin, J.; Li, Y.; Li, Y.; Wu, H.; Yu, F.; Jia, M.; Yang, X.; Wu, S.; Xie, L.; Ye, S.; Luo, F.; Hou, Z. Bacillus-shape design of polymer based drug delivery systems with janus-faced function for synergistic targeted drug delivery and more effective cancer. Mol. Pharm. 2015, 12, 1318-1327. [CrossRef] [PubMed]

36. Hinde, E.; Thammasiraphop, K.; Duong, H.T.T.; Yeow, J.; Karagoz, B.; Boyer, C.; Gooding, J.J.; Gaus, K. Pair correlation microscopy reveals the role of nanoparticle shape in intracellular transport and site of drug release. Nat. Nanotechnol. 2016, 12, 81-89. [CrossRef] [PubMed]

37. Tschierske, C. Development of structural complexity by liquid-crystal self-assembly. Angew. Chem. Int. Ed. 2013, 52, 8828-8878. [CrossRef] [PubMed]

38. Wang, Z.; Luo, Z.; Li, M.; Sheng, R.; Luo, L.; Cao, A. Preparation and self-assembly of PHEMAChol- $b$-PBLG diblock copolymers bearing rigid liquid crystal cholesterol grafts. Acta Polym. Sin. 2016, 5, 667-678.

39. Hosta-Rigau, L.; Zhang, Y.; Teo, B.M.; Postma, A.; Städler, B. Cholesterol-a biological compound as a building block in bionanotechnology. Nanoscale 2013, 5, 89-109. [CrossRef] [PubMed]

40. Ercole, F.; Whittaker, M.R.; Quinn, J.F.; Davis, T.P. Cholesterol modified self-assemblies and their application to nanomedicine. Biomacromolecules 2015, 16, 1886-1914. [CrossRef] [PubMed] 
41. Zhou, Y.; Ahn, S.K.; Lakhman, R.K.; Gopinadhan, M.; Osuji, C.O.; Kasi, R.M. Tailoring crystallization behavior of PEO-based liquid crystalline block copolymers through variation in liquid crystalline content. Macromolecules 2011, 44, 3924-3934. [CrossRef]

42. Lee, A.L.Z.; Venkataraman, S.; Sirat, S.B.M.; Gao, S.; Hedrick, J.L.; Yang, Y.Y. The use of cholesterol-containing biodegradable block copolymers to exploit hydrophobic interactions for the delivery of anticancer drugs. Biomaterials 2012, 33, 1921-1928. [CrossRef] [PubMed]

43. Venkataraman, S.; Lee, A.L.; Maune, H.T.; Hedrick, J.L.; Prabhu, V.M.; Yang, Y.Y. Formation of disk- and stacked-disk-like self-assembled morphologies from cholesterol-functionalized amphiphilic polycarbonate diblock copolymers. Macromolecules 2013, 46, 4839-4846. [CrossRef]

44. Jia, L.; Albouy, P.A.; Di Cicco, A.; Cao, A.; Li, M.H. Self-assembly of amphiphilic liquid crystal block copolymers containing a cholesteryl mesogen: Effects of block ratio and solvent. Polymer. 2011, 52, 2565-2575. [CrossRef]

45. Jia, L.; Liu, M.; Di Cicco, A.; Albouy, P.-A.; Brissault, B.; Penelle, J.; Boileau, S.; Barbier, V.; Li, M.H. Self-assembly of amphiphilic liquid crystal polymers obtained from a cyclopropane-1,1-dicarboxylate bearing a cholesteryl mesogen. Langmuir 2012, 28, 11215-11224. [CrossRef] [PubMed]

46. Jia, L.; Lévy, D.; Durand, D.; Impéror-Clerc, M.; Cao, A.; Li, M.H. Smectic polymer micellar aggregates with temperature-controlled morphologies. Soft Matter 2011, 7, 7395-7403. [CrossRef]

47. Jia, L.; Cao, A.; Lévy, D.; Xu, B.; Albouy, P.A.; Xing, X.; Bowick, M.J.; Li, M.H. Smectic polymer vesicles. Soft Matter 2009, 5, 3446-3451. [CrossRef]

48. Hu, F.; Chen, S.; Li, H.; Sun, J.; Sheng, R.; Luo, T.; Cao, A. Preparation of new amphiphilic liquid-crystal diblock copolymers bearing side-on cholesteryl mesogen and their self-aggregation. Acta Chim. Sin. 2013, 71, 351-359. [CrossRef]

49. Sevimli, S.; Inci, F.; Zareie, H.M.; Bulmus, V. Well-defined cholesterol polymers with pH-controlled membrane switching activity. Biomacromolecules 2012, 13, 3064-3075. [CrossRef] [PubMed]

50. Zhu, J.; Lei, Q.; Yang, B.; Jia, H.; Qiu, W.; Wang, X.; Zeng, X.; Zhuo, R.; Feng, J.; Zhang, X. Efficient nuclear drug translocation and improved drug efficacy mediated by acidity-responsive boronate-linked dextran/cholesterol nanoassembly. Biomaterials 2015, 52, 281-290. [CrossRef] [PubMed]

51. Sevimli, S.; Sagnella, S.; Macmillan, A.; Whan, R.; Kavallaris, M.; Bulmus, V.; Davis, T.P. The endocytic pathway and therapeutic efficiency of doxorubicin conjugated cholesterol-derived polymers. Biomater. Sci. 2015, 3, 323-335. [CrossRef] [PubMed]

52. Wang, Z.; Luo, T.; Sheng, R.; Li, H.; Sun, J.; Cao, A. Amphiphilic diblock terpolymer PMAgala-b-P(MAA-co-MAChol)s with attached galactose and cholesterol grafts and their intracellular $\mathrm{pH}$-responsive doxorubicin delivery. Biomacromolecules 2016, 17, 98-110. [CrossRef] [PubMed]

53. Sheng, R.; Luo, T.; Zhu, Y.; Li, H.; Sun, J.; Chen, S.; Sun, W.; Cao, A. The intracellular plasmid DNA localization of cationic reducible cholesterol-disulfide lipids. Biomaterials 2011, 32, 3507-3519. [CrossRef] [PubMed]

54. Sheng, R.; Luo, T.; Li, H.; Sun, J.; Wang, Z.; Cao, A. 'Click' synthesized sterol-based cationic lipids as gene carriers, and the effect of skeletons and headgroups on gene delivery. Bioorg. Med. Chem. 2013, 21, 6366-6377. [CrossRef] [PubMed]

55. Zhang, L.; Yu, K.; Eisenberg, A. Ion-induced morphological changes in 'crew-cut' aggregates of amphiphilic dlock copolymers. Science 1996, 272, 1777-1779. [CrossRef] [PubMed]

56. Ding, J.; Chen, J.; Li, D.; Xiao, C.; Zhang, J.; He, C.; Zhuang, X.; Chen, X. Biocompatible reduction-responsive polypeptide micelles as nanocarriers for enhanced chemotherapy efficacy in vitro. J. Mater. Chem. B 2013, 1, 69-81. [CrossRef]

57. Lv, S.; Li, M.; Tang, Z.; Song, W.; Sun, H.; Liu, H.; Chen, X. Doxorubicin-loaded amphiphilic polypeptide-based nanoparticles as an efficient drug delivery system for cancer therapy. Acta Biomater. 2013, 9, 9330-9342. [CrossRef] [PubMed]

58. Wang, Y.; Hong, C.; Pan, C. Galactose-based amphiphilic block copolymers: Synthesis, micellization, and bioapplication. Biomacromolecules 2013, 14, 1444-1451. [CrossRef] [PubMed]

59. Choucair, A.; Lavigueur, C.; Eisenberg, A. Polystyrene- $b$-poly(acrylic acid) vesicle size control using solution properties and hydrophilic block length. Langmuir 2004, 20, 3894-3900. [CrossRef] [PubMed]

60. Ambrosi, M.; Cameron, N.R.; Davis, B.G. Lectins: Tools for the molecular understanding of the glycocode. Org. Biomol. Chem. 2005, 3, 1593-1608. [CrossRef] [PubMed] 
61. D'Souza, A.A.; Devarajan, P.V. Asialoglycoprotein receptor mediated hepatocyte targeting-Strategies and applications. J. Control. Release 2015, 203, 126-139. [CrossRef] [PubMed]

62. Kim, B.S.; Hong, D.J.; Bae, J.; Lee, M. Controlled self-assembly of carbohydrate conjugate rod-coil amphiphiles for supramolecular multivalent ligands. J. Am. Chem. Soc. 2005, 127, 16333-16337. [CrossRef] [PubMed]

63. Aggarwal, P.; Hall, J.B.; McLeland, C.B.; Dobrovolskaia, M.A.; McNeil, S.E. Nanoparticle interaction with plasma proteins as it relates to particle biodistribution, biocompatibility and therapeutic efficacy. Adv. Drug Deliv. Rev. 2009, 61, 428-437. [CrossRef] [PubMed]

64. Patil, S.; Sandberg, A.; Heckert, E.; Self, W.; Seal, S. Protein adsorption and cellular uptake of cerium oxide nanoparticles as a function of zeta potential. Biomaterials 2007, 28, 4600-4607. [CrossRef] [PubMed]

65. Shan, X.; Liu, C.; Li, F.; Ouyang, C.; Gao, Q.; Zheng, K. Nanoparticles vs. nanofibers: A comparison of two drug delivery systems on assessing drug release performance in vitro. Des. Monomers Polym. 2015, 18, 678-689. [CrossRef]

(c) 2018 by the authors. Licensee MDPI, Basel, Switzerland. This article is an open access article distributed under the terms and conditions of the Creative Commons Attribution (CC BY) license (http://creativecommons.org/licenses/by/4.0/). 